\title{
O lógico, o lógico-matemático e a crítica da economia política do espaço: elementos para um debate
}

El lógico, el lógico-matemático y la crítica de la economía política del espacio: elementos para un debate

Le logique, le logico-mathématique et la critique de l'économie politique de l'espace : éléments pour un débat

The logical, the logic-mathematical and the critique of political economy of space: elements for a debate

\section{Marcio Rufino Silva}

\section{(2) OpenEdition}

Journals

Edição electrónica

URL: http://journals.openedition.org/espacoeconomia/3008

DOI: 10.4000/espacoeconomia.3008

ISSN: 2317-7837

\section{Editora}

Núcleo de Pesquisa Espaço \& Economia

Refêrencia eletrónica

Marcio Rufino Silva, «O lógico, o lógico-matemático e a crítica da economia política do espaço: elementos para um debate », Espaço e Economia [Online], 10 | 2017, posto online no dia 27 julho 2017, consultado o 19 abril 2019. URL : http://journals.openedition.org/espacoeconomia/3008; DOI : 10.4000/espacoeconomia.3008

Este documento foi criado de forma automática no dia 19 Abril 2019.

(c) NUPEE 


\section{O lógico, o lógico-matemático e a crítica da economia política do espaço: elementos para um debate}

El lógico, el lógico-matemático y la crítica de la economía política del espacio: elementos para un debate

Le logique, le logico-mathématique et la critique de l'économie politique de

l'espace : éléments pour un débat

The logical, the logic-mathematical and the critique of political economy of

space: elements for a debate

Marcio Rufino Silva

\section{Episódios de uma situação social crítica}

Resumindo, o que encontrará o leitor nessas páginas? Um projeto ou "o" projeto de sociedade? Não e sim! Primeiramente, não. O livro busca, antes de tudo, apresentar, renovando um pouco, um caminho, um projeto dialético: o pensamento dialético. Porém, ele tenta igualmente trazer alguns elementos de um projeto prático (concernente, então, à sociedade). Ele parte de uma espécie de axioma ou de um postulado, que muitos recusam de início: os "modelos", o "capitalismo" e o "socialismo", caem sob o esgotamento e a obsolescência. Lentamente, porém certeiramente. (LEFEBVRE, 1986, p. 14)

1 Nestes cinzentos dias que marcam a virada da primeira para a segunda metade do ano de 2017, a economia e a política rendem polêmicas e angústias mundo afora. Ensaiando um exercício de análise de conjuntura, as cinzas se colocam desde as peripécias xenófobas e neo-imperialistas do executivo estadunidense ocupado pelo megaempresário Donald Trump (incluindo o "impedimento" de cidadãos de nove países da África e Ásia - do eixo do assim chamado "Oriente Médio" - de ingressarem em solo pátrio estadunidense, bem como as conhecidos e perigosos reclames de "liberdade" e "democracia" para as "ditaduras comunistas" da América Latina, por parte das mesmas forças políticas) até as 
desventuras fluminenses (do estado do Rio de Janeiro) de um atraso um pouco mais estendido dos salários dos servidores públicos estaduais, dos quase "naturalizados" dois meses para três meses sem a pecúnia básica. Nada de muito novo sob o império da passividade moderna, lembrando famoso dito situacionista de fins da década de 1960, este que completa cinquenta anos com um invejável shape pós-adolescente. 0 eterno presente se realiza pela coagulação do espaço-tempo.

2 Em abril de 2017, a agência russa de notícias Sputnik divulgou depoimento do "especialista em relações internacionais" e "ex-diplomata venezuelano" ${ }^{1}$ Ghazi Nassereddine, que os Estados Unidos estariam "preparando o terreno na América Latina" de modo a construir uma "intervenção a longo prazo", criando "uma situação muito semelhante à do Oriente Médio". ${ }^{2}$ Para o estudioso/especialista/ex-diplomata consultado por agências russas de imprensa, seria necessário fazer uma avaliação, "a nível mundial", do fluxo do "pensamento salafista-wahhabita", atribuindo a essas tendências ultraconservadoras do islamismo a fonte primordial da organização futura de grupos terroristas. A partir de uma suspeita do possível fluxo de tais grupos pela América Latina, Nassereddine pontifica que "os governos da região, sejam de esquerda ou de direita", não possuiriam "maturidade política e governabilidade necessária para prevenir essa situação", reiterando a extrema vulnerabilidade desse território a essas esferas de ação. A espreita de perspectivas mais "sofisticadas" e "avançadas" de imperialismo para além da assim chamada "dominação econômica" via ajuste fiscal e outras peripécias neoliberais pós-neodesenvolvimentistas abre um perigoso flanco para uma guerra aberta, essa "política por outros meios" em terras latino-americanas.

3 Do solo especificamente brasileiro, Igor Fuser destaca o "nada" da atual política externa brasileira, praticada, desde maio de 2016, pelo ex-ministro das Relações Exteriores, o Senador paulista José Serra, e pelo atual, o também Senador e também paulista Aloysio Nunes. ${ }^{3}$ Como uma contraposição à política externa "ativa e altiva" do período 2003-2016 (com todas as suas nuances, ênfases e crises momentâneas), a atual "política externa" brasileira atual resumiria-se a um "alinhamento incondicional aos Estados Unidos em todos os temas, fóruns e instâncias do sistema internacional", uma "adesão irrestrita à globalização neoliberal" e, por último, um "envolvimento ostensivo na campanha internacional para depor o presidente venezuelano Nicolás Maduro", em uma tentativa de esmagamento da "Revolução Bolivariana" e de entrega do poder central à "direita local", também aliada dos Estados Unidos. Lembrando a "doutrina" martelada pelo parlamentar cearense/baiano Juracy Magalhães, logo que assumira o posto de Embaixador do Brasil em Washington após a quartelada de 1964 ("o que é bom para os Estados Unidos é bom para o Brasil"), Fuser destaca as medidas de alinhamento automático do governo golpista de então aos interesses estadunidenses: rompimento de relações com Cuba, envio de tropas brasileiras à República Dominicana no golpe de Estado naquele país em 1965 e a proposta (posteriormente não realizada) de envio de tropas tupiniquins ao Vietnã. As peripécias dos representantes atuais do "governo golpista" trazido à luz em 2016 não deixam por menos: desde o esvaziamento tático e estratégico da presença brasileira na Unasul, Celac e Brics até a "pressa" no selamento (fracassado, sobretudo devido à vitória eleitoral de Donald Trump na presidência dos EUA) do Acordo Transpacífico de Comércio e Investimentos (o "famoso" TPP). Finalizando, ao ironizar a "viralatice" dos "neoliberais tupiniquins" que se arrogam em "ser mais realistas que o rei", Fuser denuncia o "entreguismo" de blocos de exploração petrolífera a preços módicos a empresas estrangeiras, as negociações da cessão do centro de lançamento de foguetes de Alcântara, 
no Maranhão, às "Forças Armadas dos Estados Unidos" e a "irresponsável" participação ativa do governo brasileiro na desestabilização do atual governo venezuelano, a exemplo do ocorrido no momento imediato pós-golpe militar (e empresarial) no Chile, em 1973. Se a história não se repete como tragédia, mas como farsa, tal assertiva hegeliana/marxiana proferida em meados do século 19 para nomear o golpe de "18 Brumário de Luís Bonaparte" segue com uma atualidade terrivelmente desconcertante.

Ainda quanto ao Brasil, o editor Saul Leblon comenta o "exílio" de elementos da alta "elite" nacional de solo pátrio: especificamente, sócios privilegiados da banca rentista, controladores de fundos de investimentos e banqueiros envolvidos em maior ou menor grau com o "centro" da gestão da política econômica brasileira. ${ }^{4}$ Tais personagens, especificamente Pérsio Arida ("o ex-menino prodígio do Plano Real" e ex-presidente do Banco Nacional de Desenvolvimento Econômico e Social [BNDES] na era de Itamar Franco [1993-1995]) e André Lara Resende (igualmente ex-presidente do BNDES, já em meados da era FHC [1998]), exemplificam o "êxodo" mapeado por Leblon, verificável na quantidade de Declarações de Saída Definitiva do Brasil, em dados da Receita Federal: de 8.510, em 2011, para 20.469, em 2016. A leitura do editor, ardoroso defensor do "destravamento" de um "novo ciclo de investimento no país", caminha no sentido de denunciar uma situação social na qual a garantia da "remuneração da riqueza privada", que "tem na dívida pública a sua contrapartida de miséria", seria o resultado mais palpável da sublevação do "mercado", da "mídia" e da "escória política" na derrubada do governo de Dilma Rousseff, há cerca de um ano. Desse modo, "nem o Estado investe em infraestrutura" e "nem os gestores privados querem correr o risco", garantindo um futuro "esfarelado" nas "remessas imediatistas das grandes corporações". O embotamento do tempo-espaço revela justamente os limites dessa modalidade crítica de acumulação: o choro lamentoso para uma "elite" que "abdicou" de "responsabilidades e valores compartilhados" é o que clama pela "nação" em lugar de um "ajuntamento demográfico" puro e simples. 0 "nacionalismo", em um mundo que progressivamente varre as "economias nacionais" diante da crise, aparece como um amargo holograma de tempos "gloriosos" varridos para um futuro de novas associações possíveis em um novo "pacto" nacional para o desenvolvimento. No caso do Brasil, um novo "ciclo de desenvolvimento" aproveitar-se-ia das "potencialidades" pouco exploradas de seus recursos naturais e humanos. Nesses tristes dias que correm, um outro lamento lacrimoso tem feito parte da constatação da tragédia desprovida de futuro: "o velho ainda não morreu e o novo ainda não nasceu", diria as emulações gramscianas.

5 David Harvey, em "17 contradições e o fim do capitalismo" (2016), distingue três "categorias" de contradições próprias a este vigente modo de produção (segundo a obra de Marx e Engels) ou o "sistema de metabolismo social" e seus "sistemas de mediações" (segundo leitura de Ricardo Antunes, baseando-se em obra de Istvan Mészáros): as "contradições fundamentais", as "contradições mutáveis" e as "contradições perigosas". Uma das "contradições perigosas" mais expressivas apontadas pelo geógrafo britânico consiste justamente no "crescimento exponencial infinito". Como é possível esse "infinito"? Quais as suas consequências sociais e políticas? Que lógicas comandam essa realidade?

6 Em uma afirmação surpreendentemente simples, Harvey revela uma realidade: "a maioria das pessoas não entende a matemática dos juros compostos", e sequer "o fenômeno do crescimento exponencial (ou composto)", bem como "o perigo potencial que ele representa" (2016, p. 207). Se, em um passado mais "glorioso" das primeiras "revoluções 
industriais", os "ciclos de inovação" correspondentes foram suficientes para garantir o crescimento ilimitado do "consumo real per capita", os ciclos posteriores à década de 1960, embora tenham efetivado pequenas "revoluções" no campo da cultura do consumo espetacular ao nível individual e social (os gadgets em geral), não foram capazes de atender a esses anseios globais. Desse modo, até mesmo a medida subjetiva de riqueza se transforma inclusive ao nível do senso comum, nível esse que torna simplesmente incomensurável qualquer medida em relação às bolhas cifradas de "riquezas" que circulam nas altas esferas da economia fictícia. De fato, as casas dos "bilhões" e "trilhões" são pouco apreensíveis em escalas que mal ultrapassam os "milhares". E Harvey, mais adiante, menciona a metafísica cifra "ótima" de $3 \%$ de crescimento composto ao ano, limite que separa as economias "saudáveis" daquelas "letárgicas" ou "depressivas". É a "taxa de retorno positiva sobre o capital" (2016, p. 213), considerando criticamente as leituras visivelmente biologicizadas no campo analítico mais raso, e mesmo aquelas de caráter mais "científico", ressuscitando um neopositivismo não muito distante do clássico positivismo de fins do século 19.

7 Mas os juros compostos (considerando, também, que os juros simples não afastam muito o problema, apenas o atenuam um pouco...) trazem situações bizarras. Desde a "matemática social" malthusiana e a sua contestação parcial pela realidade materialmente históricogeográfica (sobretudo pela chamada "transição demográfica", onde a população mais idosa supera a população mais jovem) até as tentativas de emulação do padrão de "crescimento" e "desenvolvimento econômico" estadunidense (século 20) e chinês (século 21), de que modo "o capital pode continuar a se acumular e se expandir perpetuamente a taxas compostas" (HARVEY, 2016, p. 216)? Não seria a forma-dinheiro a permitir essa acumulação sem limites? E não seria justamente esse dinheiro tornado ficção a cumprir esse papel? Dinheiro esse calibrável pelos mecanismos bélico-produtivos da maquinaria de dólar comandada pelos Estados Unidos em par com a China e as "economias dinâmicas" do mundo pseudo-produtivo, bem como pelo achatamento universal do "poder de compra" via esmagamento dos salários, desemprego em massa e a cada vez mais banalizada descartabilidade humana universal, sem contar ainda a popularização dos créditos e microcréditos a permitirem o azeite de uma máquina falida e o comprometimento perpétuo do futuro individual e coletivo.

8 Se as novas marés de "desenvolvimento econômico" hoje parecem uma mentira tão mal contada quanto confessadamente revelada em benefício da sobrevivência ampliada, esse campo lógico e social, pautado pela cisão universal e o automovimento do dinheiro em sua forma mais abstrata, traz o seu alcance e o seu limite. 0 fluxo de uma política alienada atrelada a uma economia terrorista, no escopo de uma sociabilidade pautada pela vida ao fio da navalha, no limiar constante entre a vida e a morte, é o substrato necessário dessa ordem social profundamente tautológica.

9 Encerrando nossa "análise de conjuntura", a tautologia dessa sociedade é manifesta por Luis Casado, refletindo a respeito do "grande salto atrás" da "Economia Política". ${ }^{5}$ Casado não traz boas notícias aos simpatizantes da pouco simpática Economia Política: uma figura como o "Chicago-boy" Milton Friedman já afirmava, nos píncaros de sua homilia monetarista, que a grande "novidade" daquela ciência (e da prática) era justamente o veterano e clássico "Adam Smith". A exemplo do que Henri Lefebvre, em clássico texto onde o filósofo/sociólogo francês construía a sua "crítica da economia política do espaço" (2008 [1973]), Casado, apoiando em citações de Bernard Maris (jornalista/economista francês morto no massacre do Charlie Hebdo, em janeiro de 2015), expõe o caráter 
desiludido dos "primeiros economistas" (mais especificamente, Jean-Baptiste Say e Adam Smith) quanto a essa "ciência econômica, a ciência do mal", ou "a ciência sinistra": a Economia Política. Além disso, o economista (que, na visão de Casado/Maris, "não passa de um vigarista, um charlatão que esconde em seu palavrório, geralmente complicado, o objetivo imposto por seus senhores, que é manter os homens na servidão") é o ser que, personificando "o canto gregoriano da submissão do homem", fez Marx e John Maynard Keynes tentarem, sem sucesso, "libertar o homem da economia". Adiante, a exposição de Casado quanto à presença dos vilipêndios "atuais" dessa economia vodu (truques da dupla contabilidade, os monopólios, o tráfico de influência, o conflito de interesses, o engano, a fraude, o golpe, o roubo, a arbitrariedade, a pilhagem, a exploração, a dissimulação, a informação privilegiada, os privilégios, a incúria, a prevaricação, as propinas, a usura, o abuso do poder, a conspiração etc.) já nos primórdios da "transição" do Feudalismo ao Capitalismo, na "Baixa Idade Média" eurasiática, completa o ciclo descurado de um farsesco eterno retorno. Seja como for, se essa economia (enquanto prática ou lógica social e enquanto ciência) parece monstruosa e incontrolável, não seria justamente ela uma base fundamental para o desvendamento das contradições próprias do mundo moderno?

\section{Lógicas, matemáticas e métricas: uma aproximação com a obra de Henri Lefebvre}

10 Entre coágulos e fluxos acelerados, surge um importante retrato de nossos dias. 0 geógrafo Diego Ruiz, em "La reforma métrica" (2017), traz uma interessante análise a propósito da perspectiva das medidas e, mais particularmente, do Sistema Métrico Decimal e do Tempo Universal Coordenado, na construção de uma moderna "sóciológica" no espaço urbano latino-americano. Seu "recorte espaço-temporal", localizado no Rio de Janeiro e na Cidade do México de fins do século 19 e da primeira metade do século 20, traz uma contribuição ímpar para o desvendamento da imissão dessas lógicas ao campo social.

11 Questionando-se a propósito das formas e conteúdos implicados a essas "medidas" padronizadas, como fundamento teórico-prático da normatização dos produtos e da produção, afirma o autor, trazendo elementos do "direito à preguiça" preconizado por Paul Lafargue:

A distribuição da riqueza e dos meios de produção deve conter uma proposta a respeito dos sistemas de medição. Aquela proposta não pode ser gerada a partir do que eu chamo de nossa compreensão fragmentada da medição e as medidas. A fragmentação à qual me refiro inicia-se no momento de dividir o espaço com o tempo. Já separado o tempo, a medição se divide em "pesar" e "medir". Aquela operação mental, que dota de certas características a um objeto $x$ com a finalidade de compará-lo com um outro $y$, ocorre para o tempo, a longitude, o peso, o nível de álcool do sangue ad infinitum. Falta uma explicação que quebre com a segmentação de nosso entendimento sobre a medição e essa explicação poderia formular-se a partir da Geografia. Será porque a mudança da qual quero falar no "medir" e no "pesar" coincidiram com uma mudança na medição do tempo? (RUIZ, 2017, p. 2)

12 Adiante, ao trazer os "elementos cotidianos" dessa metrificação, a associação entre essa realidade e o campo analítico da chamada "ritmanálise", conforme proposição desenvolvida mais ou menos tardiamente na obra de Henri Lefebvre, o autor expõe a perspectiva da "cidade semáforo". Em termos gerais, tal "proposta conceitual" refere-se à "sincronização dos tempos das pessoas em relação a um tempo legal único que determina 
e regula um espectro que vai desde os segundos até os anos" (2017, p. 11). A sincronização desses tempos, "responsável por temporalidades hierárquicas". Amiúde, trata-se de uma "cidade-plano cartesiano", uma eterna "cidade-projeto", compostas por uma "verticalização falocrática"... Uma cidade (um espaço-tempo) na qual outros sistemas de medição seguem convivendo com os banais metros, gramas e horas e onde tal reles banalidade é constantemente assaltada em sua pretensão universal. Como medir o corpo? Como medir o vivido? Como medir o espaço?

No momento atual, mostra-se sobremaneira evidente o quanto as estratégias do espaço se põem a serviço da realização de uma economia crítica, expondo os limites e as fronteiras da valorização do valor, em suas múltiplas escalas.

Para tanto, há que se colocar o expoente de uma composição no campo da política, não se restringindo apenas à ideia de uma crítica à política pública em si, o que consideramos insuficiente ao tratamento do problema que expomos neste artigo. Uma crítica desse quilate, dependendo de seu viés político ou ideológico, poderia servir muito mais ao aperfeiçoamento do Estado e de sua lógica da equivalência, ou de seu assentimento ao funcionamento da maquinaria social urbana, do que propriamente a uma crítica que se pretenda, de fato, radical.

Assim, voltemo-nos ao que Lefebvre nos ensina a respeito.

\section{Uma leitura a partir da obra de Henri Lefebvre: tática, estratégia, operador e operatório.}

A proposição lefebvreana sobre as táticas e estratégias aparece em variados momentos de sua obra, sobretudo no segundo volume da Crítica da vida quotidiana II ([1961] 1980), no quarto volume da coleção Estado (1978), em O manifesto diferencialista (1970) e, mais sistematicamente, em $O$ retorno da dialética (1986). Em relação à primeira obra citada, tratando especificamente da vida cotidiana enquanto um nível da prática social, e a sua crítica enquanto uma possibilidade concreta do conhecimento e desvelamento dessa mesma vida quotidiana, o autor afirma que:

O estudo crítico da vida cotidiana desvelará a tática e a estratégia dos grupos parciais (as mulheres, os jovens, os intelectuais etc.) na sociedade global. Ela saberá revelá-los, através das ambiguidades, o quanto elas se revelam e se significam, o quanto elas se revelam e se dissimulam, mas ainda assim se expressam. 0 estudo da cotidianidade apreenderá as relações dos agrupamentos que os tornam opacos em seus contatos, ou que os fazem acessíveis uns aos outros, a despeito dos malentendidos, das manobras táticas, dos disfarces, das aberturas e aventuras estratégicas. [...] Quanto aos momentos nos quais predomina a estratégia, são justamente esses os grandes momentos históricos, as efervescências. A estratégia confere o sentido dos grupos e de sua vida. O "sentido", direção, orientação, expressão e objetivo, não tem nada de uma tranquila entidade especulativa, a ser filosoficamente desobstruída por um especialista, o filósofo. O sentido é o drama. É a estratégia - referente ao grupo - que o constitui. Ela o cria. O nível da cotidianidade enquanto "realidade" seria, portanto, aquele da tática, intermediário entre o nível onde não há mais o ato, onde a realidade estagna e se espessa, onde domina o trivial - e o referente à decisão, ao drama, à história, à estratégia e à revolução. (LEFEBVRE, 1980 [1961], pp. 138-139)

17 E este seria o sentido, então, das táticas e estratégias ao nível do vivido entre diversos agrupamentos sociais, tomando os períodos dominados pelas estratégias como os grandes 
momentos históricos, pelo menos por parte desses chamados "grupos parciais". No entanto, predominando a tática, temos em mãos somente o espessamento da vida tornada "realidade" e toda a sorte de ambiguidades decorrentes da imissão dessa vida chamada "real". A cotidianidade seria, assim, o reino das táticas. Quanto à estratégia, poderíamos lê-la enquanto uma tomada efetiva do tempo da história, superando a banal linearidade do tempo pseudocíclico?

Quanto à obra Estado, o autor trata especificamente das estratégias que se levam adiante a partir do viés estatista, afirmando que "o conceito de estratégia e a prática correspondente tomam uma importância capital", colocando, logo a seguir, que "toda estratégia implica uma lógica", aplicada a uma situação, "a recursos, a objetivos e alvos, à lógica geral (logística)". Vale a pena seguir um pouco mais o raciocínio do autor a respeito:

A teoria das estratégias modifica sem abolir a análise clássica da ação como tríade: "determinismos-riscos-vontades". É verdade que ela coloca em primeiro plano o cálculo, referente aos recursos e às possibilidades: o cálculo não suprime nem as decisões e nem as chances. A parte cega da ação histórica (os homens fazendo sua história sem saber ao certo o que fazem, sem saber onde suas ações os levam, segundo Marx) tende a diminuir. $O$ que não quer dizer que ela desapareceu. De qualquer forma, os interesses particulares, tanto no socialismo de Estado quanto no capitalismo de Estado, se subordinam à coesão do conjunto político e à coerência ofensiva ou defensiva da estratégia. As separações desvanecem entre o econômico, o social, o político, e também entre o legislativo, o executivo e o político. Caem as separações, substituídas pela lógica do poder separado (gerando pelo alto, a sociedade) e, no entanto, perpassado a sociedade inteira, portanto onipresente. 0 que Hegel, primeiro, concebeu. (LEFEBVRE, 1978, p. 24)

Quanto à coerência e à coesão do conjunto político e da ação defensiva ou ofensiva do Estado, conforme apontado pelo autor, bem que poderíamos tomar, ainda, a lógica implicada às táticas e estratégias operadas a partir da ação estatista. Em $O$ manifesto diferencialista, o autor ressalta a complexidade de uma forma social que não se desdobra em apenas uma lógica, e sim em várias lógicas, ou seja, "vários procedimentos para impor uma consciência", a saber: "uma lógica do repetível (combinatório), uma lógica do espaço, uma lógica das trocas e da coisa, uma lógica das significações etc.". Considerando a pluralidade dessas lógicas, Lefebvre coloca, ainda, que tal pluralidade "proíbe a coerência que elas desejam estabelecer", sendo "essas múltiplas sócio-lógicas e ideo-lógicas" impeditivas à "constituição de um sistema fechado, ainda que haja ininterruptamente tentações (sobre o plano ideo-lógico) e tentativas (sobre o plano sócio-lógico) de fechamento e conclusão". Avante no raciocínio do autor:
A racionalidade limitada se limita inevitavelmente às táticas. O fetichismo da coerência e o da eficácia dissimulam essa redução. E, no entanto, há estratégias. Teriam elas seus lugares de formulação e de aplicação fora do pensamento que se diz teórico? Certamente. Onde? Entre os políticos? Talvez, mas sobretudo entre os militares. Quando aos técnicos e tecnocratas, eles só podem ter um primeiro objetivo, o de tornar capazes de uma estratégia, ou seja, de se erigir em grupo, casta ou classe. (LEFEBVRE, 1970, p. 100-101)

Quanto ao trabalho, no interior da lógica estatista e de sua afirmação rumo à interposição da equivalência como seu fundamento, bem que o expediente militar à tática e estratégia conduziria, para muito além de uma banal e metáfora gratuita, a uma lógica imanente à forma e ao conteúdo da equivalência: a guerra. E não poderia ser tomado como um simples adereço pitoresco ou folclórico determinadas políticas e/ou falas de representantes políticos e/ou agentes econômicos mais ou menos farsescos ou ridículos: trata-se, efetivamente, de uma guerra, um conjunto de batalhas táticas, de modo a renovar os 
territórios e lugares e a colocá-los, efetivamente, na exposição universal das mercadorias e fundos de investimentos.

Desse modo, todo o território, toda a sociedade e todo o espaço tornam-se, enfim, estratégia! Espacialidade, portanto, suprimindo a temporalidade, impondo uma sócio-lógica, uma ideo-lógica, conforme os termos apontados em Lefebvre. E isso não é tudo. Ainda no pensamento lefebvreano a respeito dessa lógica se interpondo à forma social, invadida pelos ritmos e ditames da maquinaria mundializada de valorização do valor, fiquemos com um expressivo texto, publicado já na segunda metade da década de 1980, quando formas mais aprofundadas de estratégias do espaço se punham à mesa do aludido planejamento urbano e suas congêneres políticas públicas. Vejamos.

Em 0 retorno da dialética, o qual o autor propunha ser "um livro-ação, um guia no labirinto do mundial", onde "cada 'artigo' almeja oferecer uma entrada em um conjunto a compor seus fragmentos, em uma perspectiva e uma concepção que não concluem, que não se completam", (LEFEBVRE, 1986, p. 11) destaca-se o tratamento a "doze palavras-chave para o mundo moderno", onde o Estado é justamente a primeira palavra a ser contemplada. Destilando o sentido lógico e histórico da afirmação do Estado moderno, Lefebvre afirma, por exemplo, que "o Estado-nação perfeito realizaria a identidade perfeita", ou seja, a partir da "redução das diferenças, homogeneidade dos elementos, localização e fracionamentos controlados". Continuando, afirma que "cada estratégia comporta uma lógica", facilitando "a tarefa dos cientistas da computação", mas que não contribuiria "com a tão desejada coesão da sociedade" (1986, p. 28).

E já que ingressamos nessa seara, seguindo o raciocínio do autor e relacionando suas concepções ao teor dos acontecimentos conjunturais elencados no início deste texto, partamos, enfim, rumo às suas considerações a respeito do(a) lógico(a) e do(a) lógicomatemático. Em primeiro lugar, considera-se o ingresso do(a) lógico(a) na prática social, não "pela única ação potente do pensamento", mas a partir de extrema violência, cuja relação com o(a) lógico(a) se põe a partir de "toda ação levada de modo coerente, não somente a partir do individual e de tais indivíduos que dirigem tal ou tal operação". Assinalando que "há luta constante entre a(o) lógica(o) e a dialética", (ibid.: 60) cabe refletir sobre as considerações do autor a respeito da negatividade:

À imensa positividade regida pela lógica nos diversos domínios (poderíamos dizer: no reino ou no império do lógico) se opõe uma negatividade, não menos formidável. 0 que caracteriza a modernidade: inverso e reverso. Aqui, não se trata de uma oposição abstrata e paradigmática, produtora de significações e de sentido, mas de um conflito prático, em profundidade: de um trabalho de destruição e de autodestruição, imanente ao "real". Se é verdade que o que insistimos nomear ingenuamente de "crise" não se circunscreve mais ao econômico, ou a esta e àquela ideologia, essa palavra designa um vasto processo que estremece a cultura, depois o político, o econômico, o Estado e, em seguida a totalidade (constituindo essa totalidade pela via da negação, e de modo algum, como acreditaram os hegelianos e muitos outros, pela via do afirmativo e do positivo). (LEFEBVRE, 1986, p. 64)

Contudo, a lógica se destacaria da filosofia, ingressando no saber e na prática. De que modo? Afirmando o reclame pela lógica "em todos os lados", o autor incorre na abordagem das matemáticas e sua intrínseca relação à lógica. Partindo da tautologia $\mathrm{A}=\mathrm{A}$, tomada clara $\mathrm{e}$ inteligível, porém vazia, redundante, poder-se-ia tomar a vastidão da tautologia operada a partir do zero e do um, onde inúmeras combinações (sequências, somas etc.) conduzem ao domínio das matemáticas, "ciência da quantidade". A partir das "propriedades" dos números (par, ímpar, números primos etc.) e as suas infinitas possibilidades (equações 
“indecidíveis", a sua qualidade de infinitude etc.), parece que a rigorosa lógica formal teria recaído, pela sua própria natureza, em certos paradoxos, cuja demonstração, "da prova pela dedução", preparariam a desforra da dialética. Mas, persistindo na forma...

Caso famoso: conta-se que Gauss, ainda criança, com oito ou nove anos, foi conduzido pelos seus pais à escola de sua aldeia. 0 mestre de escola, para verificar o nível intelectual e de instrução do novo aluno, perguntou-lhe: "Um e um, isso dá...?" "Dá um", respondeu a criança; obstinadamente. O professor, conforme se conta, o reenviou para sua casa, como débil mental. Os pais retornaram e disseram: "Mas ele já faz cálculos muitos sábios..." O professor refez a questão. Mesma resposta. A criança apenas adicionou: "Um mais um, isso dá dois". - Ele libertou da tautologia a noção de operação, ato mental produtivo, que ajunta algo (a menor diferença) ao dado. O mais difere do $e$, o qual implica a simples repetição ao idêntico. $O$ ato mental pode também remover e subtrair, cortar (segmentar, fazer um corte), fazer deslizar, ou rodar etc. A noção de operador está liberada de uma prática: a operação, ato mental cumprido desde os tempos mais remotos. Ela se generaliza recentemente; as linguagens das máquinas definem as operações lógicas, antes de definir as operações próprias. A teoria das formas permite elucidar o conceito de operador, sem esgotá-lo, no entanto. A forma "pura", a identidade, A é A, vazia, tem, entretanto, uma capacidade produtiva (e não somente reprodutiva). (1986, pp. 68-69)

O operador, assim, contendo uma potência produtiva, para além da mera tautologia da reprodução, demonstraria a operação do pensamento: em primeiro lugar, "o rigor lógico, o mesmo, o silogismo, a demonstração"; em segundo lugar, "na prática”, a identidade engendrando outras formas, "inteligíveis", não sem alguns resíduos, tais como "a equivalência, a simultaneidade, a reciprocidade"; e, finalmente, em terceiro lugar, engendrado a "ilusão filosófica concernente ao Ser idêntico (que é o que é), a Substância, a Verdade, o Absoluto". E todas essas formas, para Lefebvre, ingressariam na prática, confeririam as operações e operadores. E tudo é tornado simultâneo. E toda a maquinaria se põe, efetivamente, a funcionar, e a gerar, captar e reciclar valor, seguindo a linguagem exata e rigorosamente lógica dos documentos oficiais quanto aos "rumos" e "estratégias" futuras para a sobrevivência econômica de um mundo conflagrado em uma economia moribunda.

E toda a violência, decorrente desses atos mentais, lógicos, acontece na prática, apesar de sua não-ocorrência nas matemáticas, onde simplesmente opera o operador tout court, sem muitas mediações.

Desse modo, um ato mental põe e simultaneiza essa sequência indefinida de números gerados uns após os outros; nascem assim as noções capitais de conjunto, de infinito demonstrável, de transfinito. A potência da forma, tornada operacional, gerou ou engendrou (não somente produziu) alguma coisa de nova. O repetitivo e a diferença têm uma capacidade criadora. Dessa maneira, dissipa-se uma segunda ilusão dos filósofos, surgida após a primeira. "O Ser é", essa evidência não somente nada explica, mas consagra o sensível, o fenomenal e o movente ao nada. Admite-se, então, que a matemática é do pensamento; que não se deve pensá-las, mas aceitá-las enquanto pensamento já ali, não somente real, mas absoluto. Então: "Dum deus calculat fit mundus" (Leibniz). (LEFEBVRE, 1986, p. 69)

Quando Deus calculava, fez o mundo... Ou quando a maquinaria se punha a efetivamente funcionar, pela via da lógica, teria refeito o mundo? Como poderia essa lógica se tornar tão absoluta e se constituir, de fato, em um operador, aprofundando a figura da operação? $\mathrm{O}$ debate sobre as formas contemporâneas de alienação poderia incorporar esse modo de conceber a realidade: o Estado, em um período onde as formas mais críticas se reafirmam, se põem na espacialidade de um mundo onde sua tautologia relativa (um e um) produz a 
quantificação necessária (um mais um), de modo a restituir a lógica da equivalência. $\mathrm{E}$ a partir da equalização (violenta) dos desiguais, unificando as diferenças na lógica formal operada pela via estatista.7 O econômico, assim, se vê em sua almejada realização, tornada plena.

No entanto, Lefebvre aponta os limites da coerência e coesão próprias da lógica, em sua interface às matemáticas, sobretudo no tocante às contradições: afirma que, enquanto a lógica teria a sua força, conforme discutimos até aqui, a dialética teria a sua "contraforça". De que modo? O autor alude a uma possível dialetização das matemáticas, na qual a possibilidade de pensá-las admitiria a simples unidade do ponto (um "nada" e, ao mesmo tempo, um "alguma coisa", cuja sequência opera um ato mental, instaurando e dimensionando o espaço: "o mensurável e o medidor"), a alusão à linha e ao corte (repondo a questão do "contínuo e do descontínuo"), ao transfinito (números ao mesmo tempo finitos e infinitos) e aos números "primos". Para o autor, as contradições, embora aparentemente resolutas pelo mecanismo binário (zero e um), fundamental na construção das máquinas de calcular, reaparecem "sobretudo no pensamento crítico que continua", já que "o número e o pensamento do número não coincidem" (ibid.: 72).

\section{Considerações finais}

Encerrando, qual seria, assim, a relação entre tática, estratégia, operatório e operador? De modo a colocar essa questão em níveis mais avançados, a proposta é que se pese a possibilidade de se reconsiderar os termos contemporâneos das formas de alienação, seja no tempo, seja no espaço: no mundo do trabalho, da educação, da política... E que a figura do Estado seja realmente posta em questão, e que se desvelem as práticas operatórias dessa economia a partir de seus expedientes táticos e estratégicos.

O que se buscou discutir, neste texto, foi justamente a ação, o drama, a concepção e as possibilidades. Não se trata, contudo, de uma espécie de "teoria dos jogos", ou ainda uma tentativa de refinar essas ou aquelas táticas ou estratégias "político-econômicas". Trata-se de revelar, justamente, os limites intrínsecos à própria forma política, ao próprio Estado como figura primaz da alienação política contemporânea, esse grande mediador, operador e operatório, onde o consenso parece mover a inexorável razia do espaço (como no caso apresentado), manifestando-se em suas múltiplas escalas: em toda e qualquer cidade e território deste país e deste mundo.

31 O grau zero do espaço, a sua assepsia, comportando a varredura operada pela violência da lógica, incluem a tática e a estratégia, portanto, como ações coordenadas, simultâneas, operadas, de modo a efetivar e azeitar a maquinaria da valorização do valor. Trata-se, assim, de enfrentar uma sobreposição de diversas formas de alienação, e considerar o quanto a dialética, a contra-força, reporia o movimento e a contradição como fundamentos sociais, considerando a negatividade e apontando efetivos caminhos ou vias, aberturas, de modo a enfrentar essas alienações. É o drama, sempre o drama! 


\section{BIBLIOGRAFIA}

ANTUNES, Ricardo. Os Sentidos do Trabalho. 8ª reimpr. São Paulo: Boitempo, 2006.

DAMIANI, Amélia Luísa (coord.) et. al. o futuro do trabalho: elementos para a discussão das taxas de mais-valia e de lucro. São Paulo: AGB/SP. Labur/Programa de Pós-Graduação em Geografia Humana, Departamento de Geografia, FFLCH/USP, 2006.

DAMIANI, Amélia Luísa. Espaço e Geografia: observações de método. Ensaio sobre Geografia Urbana a partir da metrópole de São Paulo. 2008. 414 p. Tese (Livre Docência em Geografia Urbana). Faculdade de Filosofia, Letras e Ciências Humanas, Universidade de São Paulo, São Paulo, 2008. DEBORD, Guy. A sociedade do espetáculo. $1^{\mathrm{a}}$ ed. $4^{\mathrm{a}}$ reimpr. São Paulo: Contraponto, 2003.

HARVEY, David. 17 contradições e o fim do capitalismo. São Paulo: Boitempo, 2016.

HARVEY, David. O espaço como palavra-chave. Revista GEOgraphia, Niterói, vol. 14, no 28, pp. 8-39, 2012.

LEFEBVRE, Henri. Critique de la vie quotidienne II. Fondements d'une sociologie de la quotidienneté. Paris : L'Arche Éditeur, 1980 [1961].

LEFEBVRE, Henri. De l'État - 1. L'État dans le monde moderne. Paris : Union Générale d'Éditions, 1976.

LEFEBVRE, Henri. De l'État - 4. Les contradictions de l'État moderne. La dialectique et/de l'État. Paris : Union Générale d'Éditions, 1978.

LEFEBVRE, Henri. Espaço e política. 2ª ed. Belo Horizonte: Editora UFMG, 2008 [1973].

LEFEBVRE, Henri. Le manifeste différentialiste. Paris : Gallimard, 1970.

LEFEBVRE, Henri. Le retour de la dialectique. 12 mots-clefs pour le monde moderne. Paris : Messidor/Éditions Sociales, 1986.

LEFEBVRE, Henri. Méthodologie des sciences. Inédit. Paris : Anthropos, 2002.

MARX, Karl. Sobre a questão judaica. São Paulo: Boitempo, 2010 [1843].

RUIZ, Diego Cervantes. La reforma métrica. La medida y lo medido en la ciudad. 2017. 145 p. Dissertação (Mestrado em Geografia). Instituto de Geociências, Universidade Federal Fluminense, Niterói, 2017.

SILVA, Marcio Rufino, « Produção e reprodução: uma leitura contemporânea », Espaço e Economia [Online], 8 | 2016, posto online no dia 30 Setembro 2016, consultado o 04 Julho 2017. URL : http:// espacoeconomia.revues.org/2168; DOI : 10.4000/espacoeconomia.2168

\section{NOTAS}

1. "Exdiplomático buscado por el FBI: 'EE.UU. compra a un amigo y vende a un aliado de un día para otro"', 2 nov. 2015. Cf. https://es.rt.com/42u0. Acesso em: 3 jul. 2017.

2. "EUA buscam criar na América Latina situação militar igual à do Oriente Médio", 13 abr. 2017. Cf. https://sptnkne.ws/edPM. Acesso em: 3 jul. 2017. Cabe registar, aqui, a interessante entrevista de Ziauddin Sardar, "reformista muçulmano" paquistanês, ao periódico português 
"Público", a propósito do assim chamado "Daesh". "O Estado islâmico sempre existiu, é a Arábia Saudita". 7 dez. 2015. Cumpre destacar um trecho de sua entrevista: Até aos anos 1920, os wahhabitas eram uma seita muito minoritária e as pessoas gozavam com eles, eram considerados fanáticos iletrados sem relevância. Mas esta seita tornou-se na ortodoxia muçulmana. E hoje, há duas questões fundamentais aqui. Por um lado, os muçulmanos aceitam esta ideologia porque reverenciam a Arábia Saudita de forma acrítica. Por ser lá que estão Meca e Medina, assume-se que como o Profeta nasceu em Meca estas pessoas teriam o melhor conhecimento do islão, quando têm o pior. Por outro, as potências ocidentais, a América, o Reino Unido, a França, a Alemanha, apoiaram a Arábia Saudita e os estados do Golfo por motivos económicos e militares, eles compram as armas que estes países produzem. Ao apoiar a Arábia Saudita, ignorando o seu fanatismo, dão-lhes liberdade de acção." Cf. https://www.publico.pt/2015/12/07/mundo/ noticia/o-estado-islamico-sempre-existiu-e-a-arabia-saudita-1716649. Acesso em: 3 jul. 2017.

3. FUSER, Igor. “A política externa do nada”, 22 jun. 2017. Cf. http://outraspalavras.net/brasil/apolitica-externa-do-nada/. Acesso em: 3 jul. 2017.

4. LEBLON, Saul. "Bye, bye, Brasil”, 27 jun. 2017. Cf. http://www.cartamaior.com.br/?/Editorial/ Bye-bye-Brasil/38336. Acesso em: 3 jul. 2017.

5. CASADO, Luis. “A Economia Política e o grande salto atrás", 22 jun. 2017. Cf. http:// outraspalavras.net/posts/a-economia-politica-e-o-grande-salto-atras/. Acesso em: 3 jul. 2017.

6. Vale a pena continuar essa passagem. "Retomamos aqui, ainda, em uma outra perspectiva, enunciados anteriores. Entretanto, essas proposições não devem se prender literalmente. A cotidianidade, enquanto realidade a metamorfosear, contestável e contestada por sua crítica, se constata ao nível das táticas, das forças e de suas relações, ardis e desconfianças. É ao nível dos eventos, das estratégias, e dos momentos históricos que ela se transforma. Não fixamos estaticamente, portanto, um nível na vida quotidiana e em seu estudo. Isso resvalaria ou em direção ao baixo e ao trivial, ou em direção ao alto e ao eventual (no sentido estipulado). [...] Passando ao nível da estratégia, buscar-se-á como os grupos tendem a minimizar as chances de ganho máximas dos parceiros ou adversários - ou ao contrário a maximizar seu próprio ganho mínimo". LEFEBVRE, Henri. Critique de la vie quotidienne II..., 1980 [1961], p. 139.

7. Podemos inclusive lembrar uma importante alusão de Karl Marx à figura do Estado, em seu diálogo com Bruno Bauer, em Sobre a questão judaica. "O Estado político pleno constitui, por sua essência, a vida do gênero humano em oposição à sua vida material. Todos os pressupostos dessa vida egoísta continuam subsistindo fora da esfera estatal na sociedade burguesa. Onde o Estado político atingiu a sua verdadeira forma definitiva, o homem leva uma vida dupla não só mentalmente, na consciência, mas também na realidade, na vida concreta; ele leva uma vida celestial e uma vida terrena, a vida na comunidade política, na qual ele se considera um ente comunitário, e a vida na sociedade burguesa, na qual ele atua como pessoa particular, encara as demais pessoas como meios, degrada a si próprio à condição de meio e se torna um joguete na mão de poderes estranhos a ele. A relação entre Estado político e a sociedade burguesa é tão espiritualista quanto a relação entre o céu e a terra. A antítese entre os dois é a mesma, e o Estado político a supera da mesma maneira que a religião supera a limitação do mundo profano, isto é, sendo igualmente forçado a reconhecê-la, produzi-la e deixar-se dominar por ela. Na sua realidade mais imediata, na sociedade burguesa, o homem é um ente profano. Nesta, onde constitui para si mesmo e para outros um indivíduo real, ele é um fenômeno inverídico. No Estado, em contrapartida, no qual o homem equivale a um ente genérico, ele é o membro imaginário de uma soberania fictícia, tendo sido privado de sua vida individual real e preenchido com uma universalidade irreal." MARX, Karl. Sobre a questão judaica, 2010, pp. 40-41. 


\section{RESUMOS}

O texto a seguir inspira-se no debate aventado pela obra "O retorno da dialética: doze palavraschave para o mundo moderno", de Henri Lefebvre, originalmente publicado em 1986. Apresentamos o trecho onde o autor discorre sobre o termo "o lógico e o lógico-matemático", contextualizando o rico debate filosófico implicado ao livro. Essa obra, uma das últimas publicações em vida do autor francês, remete ao conjunto de seu pensamento e nos traz uma valiosa contribuição para pensarmos os desdobramentos contemporâneos da economia mundial, no escopo de sua naturalização, tal como uma forma "sócio-lógica" e "ideo-lógica".

El texto a seguir se inspiró en el debate de la obra "la vuelta de la dialéctica: doce palabras chave para el mundo moderno", de Henri Lefebvre, publicado originalmente en 1986. Presentamos el trecho donde el autor discurre sobre el término "el lógico y el lógico-matemático", contextualizando la discusión filosófica implicado en el libro. Esta obra, una de las últimas publicaciones en vida del autor francés, envía al sistema de su pensamiento y en nos trae una valiosa contribución para pensar a los desdoblamientos contemporáneos en la economía mundial, en el ámbito de su naturalización, como una forma "socio-lógica” y "ideológica" “.

Le texte suivant est inspiré par le débat de l'œuvre « Le retour de la dialectique : douze mots-clés pour le monde moderne ", signée par Henri Lefebvre en 1986. On présente l'extrait où il discute le mot-clé « le(la) logique - le(la) logico-mathématique ». L'une des dernières publications de Lefebvre, l'ouvrage nous permet de comprendre l'ensemble de sa pensée, ainsi que sa contribution pour penser les dédoublements contemporains de l'économie mondiale dans la portée de sa naturalisation en tant qu'une forme « socio-logique » et « idéo-logique. »

The following paper draws inspiration from the work "The return of dialectics: twelve keywords for the modern world", by Henri Lefebvre, originally published in 1986. We present the excerpt where the author discourses about the term "the logical and the logic-mathematical", contextualizing a rich philosophical debate implied to the book. This work, one of the last publications in the life of the French author, refers to the whole of his thought and makes a valuable contribution for thinking about the contemporary unfolding of the world economy, within the scope of its naturalization, as a "socio-logic" and a "ideo-logic" form.

\section{ÍNDICE}

Palavras-chave: lógico; matemático; crítica da economia política do espaço

Palabras claves: lógico; matemático; crítica de la economía política del espacio

Mots-clés: logique, mathématique, dialectique, critique de l'économie politique de l'espace, Henri Lefebvre.

Keywords: logical, mathematical, critique of political economy. 


\section{AUTOR}

\section{MARCIO RUFINO SILVA}

Mestre e Doutor em Geografia Humana pela Universidade de São Paulo. Professor Adjunto do Curso de Geografia (Bacharelado e Licenciatura) da Universidade Federal Rural do Rio de Janeiro. Coordenador do grupo de pesquisa "Para uma crítica da Economia Política do Espaço" (UFRRJ) e pesquisador do grupo "Geografia urbana: a vida cotidiana e o urbano" (USP). Pesquisador Permanente do Programa de Pós-Graduação em Geografia (PPGGEO/UFRRJ) e Pesquisador Associado do Programa de Pós-Graduação em Desenvolvimento Territorial e Políticas Públicas (PPGDT/UFRRJ).Email: marciorufis@ufrrj.br 